\title{
Hydrodynamic modelling of the Onega River tidal estuary
}

\author{
Evgenia Panchenko ${ }^{1 *}$, Max Leummens ${ }^{2}$, and Serafima Lebedeva ${ }^{3,4}$ \\ ${ }^{1}$ Department of Land Hydrology, Lomonosov Moscow State University, Moscow, Russia \\ ${ }^{2}$ Echyden LLC, Moscow, Russia \\ ${ }^{3}$ Northern Agency for Hydrometeorology and Environmental Monitoring, Arkhangelsk, Russia \\ ${ }^{4}$ Zubov State Institute of Oceanography, Moscow, Russia
}

\begin{abstract}
Hydrodynamic conditions in a tidal estuary are very complex and depend on a wide range of factors. This was also demonstrated in the previous studies for the estuary of the Onega River, which were primarily based on the analysis of field measurements. In this paper, the results of numerical modelling performed using $1 \mathrm{D}$ and 2DH/3D «shallow water» approaches are presented, for summer and winter hydrological conditions in the Onega River estuary. The models were built and calibrated using extensive field data, which allowed assessing the opportunities to model the temporal and spatial variability of water levels, discharges, and velocities in a dynamic environment of a tidal estuary.
\end{abstract}

\section{Introduction}

Good understanding of hydrodynamics in estuarine areas plays a very important role for a wide range of industrial and human activities and also serves as a basis for analysing the ecosystem processes in such complex environments. However, the actual hydrodynamic regime of an estuary is formed under the influence of multiple factors, including tides, storm surges and river runoff, the role of which can also significantly vary in space and in time. Because of that, monitoring data is often very limited and is not able to cover all the conditions and potential situations. More extensive and detailed information about the processes in estuarine environments can be obtained by the means of numerical hydrodynamic modelling, which also opens the possibilities for simulating and analysing various extreme scenarios. But this is only possible if several different episodes are provided with comprehensive field observations for calibration and validation of the model.

The objective of this paper was to simulate the hydrodynamic regime of the Onega River estuary based on detailed field data for both summer and winter period conditions using different modelling approaches (1D, 2D depth-averaged and 3D) in order to assess the perspectives of their application as a tool for determining the required hydrological characteristics for various activities and for assisting the decision-making processes in an environment of a tidal estuary.

\footnotetext{
*Corresponding author: panchenko.zhe@yandex.ru
} 


\section{Data and methodology}

Onega River estuary is located in the south-western part of the White Sea and it can be characterized as a typical tidal river estuary with a funnel shape (Fig.1). Mean annual discharge of the Onega River is about $500 \mathrm{~m}^{3} / \mathrm{s}$. Mean annual tidal range at the mouth cross-section is about $2.4 \mathrm{~m}$. The distance, over which tidal water level oscillations become negligible, is about $26 \mathrm{~km} \mathrm{[1].}$

In order to collect the data, necessary for numerical modelling, three field campaigns were carried out at the Onega River estuary, which covered a period of a rainfall flood (river discharge $1250 \mathrm{~m}^{3} / \mathrm{s}$ ) in August of 2017 and low-flow periods with ice cover in January of 2017 and 2019 (river discharge 74.5 and $110 \mathrm{~m}^{3} / \mathrm{s}$, respectively). The available data (Fig. 1) included detailed bathymetry, water level measurements at multiple locations (Z1-8) along the estuary and discharge measurements at two cross-sections (Q1-2, limited during the winter period). In-depth information on the data collection and its analysis are presented in [2].

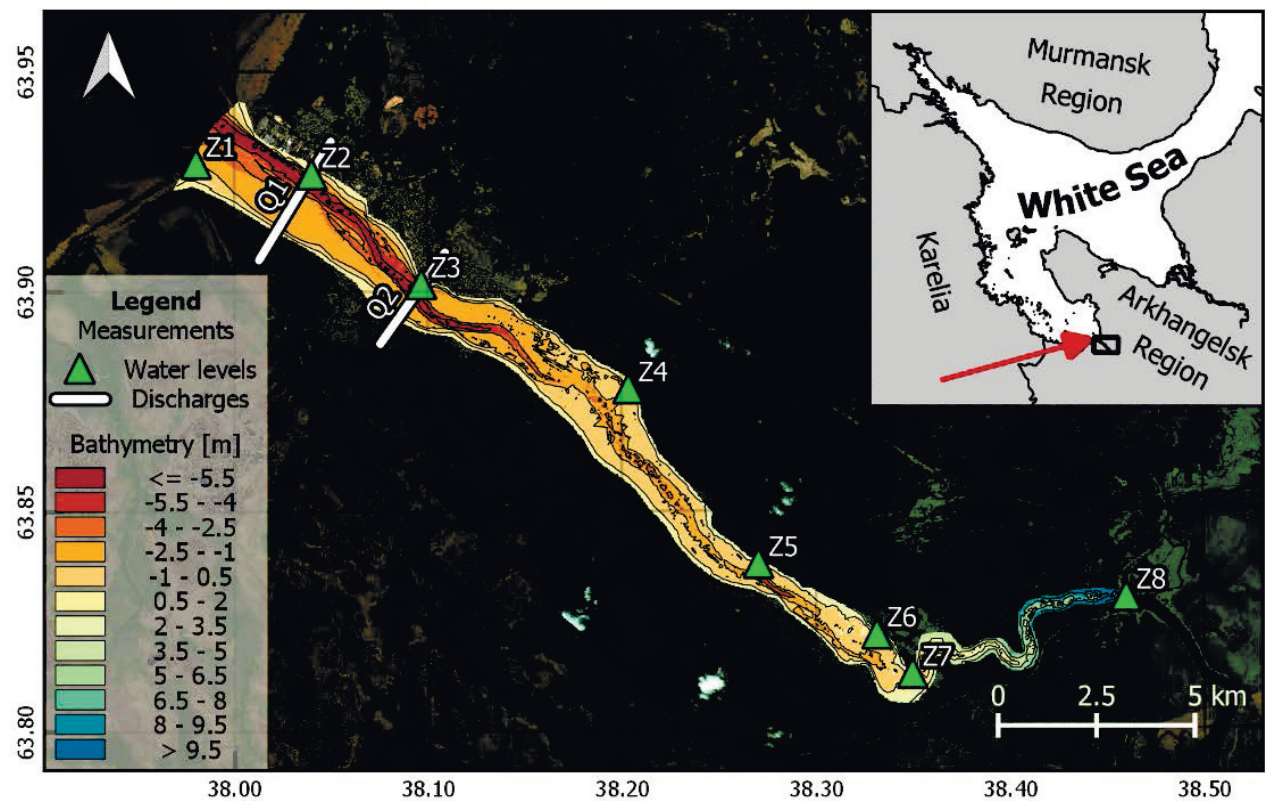

Fig. 1. Study area and the available field data.

For modelling the hydrodynamic regime of the Onega River estuary in 1D schematization, HEC-RAS software [3] solving the full one-dimensional Saint-Venant equations was used. For modelling in 2D depth-averaged (2DH) and 3D schematizations, Delft3D model [4], which is based on non-linear shallow water equations, was applied. The downstream water level boundary of the modelled area in both cases was set at the point of the river mouth cross-section, where the Onega River flows into the White Sea (location Z1). Stationary river discharge was defined on a boundary located $31 \mathrm{~km}$ upstream, near the hydrological monitoring station Porog (Z8), where the flow dynamics is no longer affected by the sea water level changes. The geometry cross-sections in the 1D model were defined with a $500 \mathrm{~m}$ step (63 cross-sections in total). For the 2DH and 3D model simulations, the same grid in the horizontal plane was used with cell size varying from about 40x20 $\mathrm{m}$ in the upstream part of the modelled area up to about 100x50 m in the downstream part. For the 3D model, 10 equal sigma layers were used in the vertical direction. 
Calibration of the 1D and 2DH models was performed separately for summer (8-9 August 2017) and winter (30-31 January 2019) periods over several tidal cycles by varying the Manning's roughness coefficient values in order to achieve the best possible model results in comparison to the measured water level sand discharges. Measurements, collected in winter of 2017 (31 January - 1 February) were used for validation of the roughness coefficients, selected for the winter conditions. Besides, as a part of calibration, the 2DH model for the summer period was also extended to a 3D model, allowing also to analyse how the model reproduces not only depth-averaged velocities, but also flow velocity profiles. Velocity measurements were also available for both winter periods; however, it was not possible to compare them to the model results because the effect of additional roughness on the water surface due to ice cover, which significantly affects the vertical velocity distribution, was not included in the model.

During the calibration process for both models in $1 \mathrm{D}$ and $2 \mathrm{DH}$ schematizations, the Onega River estuary was divided into three sections, where different values for the roughness coefficient were defined: 1 ) between 0 and $10 \mathrm{~km}$; 2) between 10 and $20 \mathrm{~km}$; 3) upstream of the $20 \mathrm{~km}$ from the mouth cross-section. Such division is determined by the morphological structure of the estuary, in which the downstream part is wide and deep with almost zero bed slope, the upstream part is highly turbulent with rapids and an average bed slope of about $1 \mathrm{~m} / \mathrm{km}$, while the middle part acts as kind of a transitional zone with bed slope of approximately $0.15 \mathrm{~m} / \mathrm{km}$.

\section{Results}

\subsection{Summer hydrodynamic conditions}

Both 1D and 2DH models after the calibration showed nearly identical results in terms of predicted water levels and discharges, however, they were obtained with different values roughness coefficient. The comparison between two models is presented in Table, from which we can see, that in general slightly higher values were used in the $2 \mathrm{DH}$ model, particularly in the downstream section of the estuary: 0.025 compared to 0.02 in the $1 \mathrm{D}$ model. The difference in values for the middle and the upstream sections is smaller: 0.032 and 0.038 in the $1 \mathrm{D}$ model and 0.033 and 0.039 in the $2 \mathrm{DH}$ model.

Table. Model calibration results: the Manning's roughness coefficient values.

\begin{tabular}{|c|c|c|c|c|c|}
\hline \multicolumn{2}{|c|}{ Period } & \multicolumn{2}{|c|}{ Summer } & \multicolumn{2}{c|}{ Winter } \\
\hline \multicolumn{2}{|c|}{ Model } & 1D & $2 \mathrm{DH}$ & $1 \mathrm{D}$ & $2 \mathrm{DH}$ \\
\hline \multirow{3}{*}{ Section } & $0-10 \mathrm{~km}$ & 0.02 & 0.025 & 0.07 & 0.08 \\
\cline { 2 - 6 } & $10-20 \mathrm{~km}$ & 0.032 & 0.033 & 0.07 & 0.08 \\
\cline { 2 - 6 } & $20-30 \mathrm{~km}$ & 0.038 & 0.039 & 0.135 & 0.135 \\
\hline
\end{tabular}

Water levels and discharges were reproduced by the models with very high accuracy in terms of their range and time moments, at which the extreme values were observed (Fig. 2). The difference between the measured and the modelled water levels on average is $1-2 \mathrm{~cm}$ and does not exceed $8 \mathrm{~cm}$ (4\% of the tidal range at the seaward boundary). For the peak flood and ebb discharges the difference between measured and the modelled values at both locations does not exceed $70 \mathrm{~m}^{3} / \mathrm{s}$, which is less than $5 \%$ of the discharge range. 

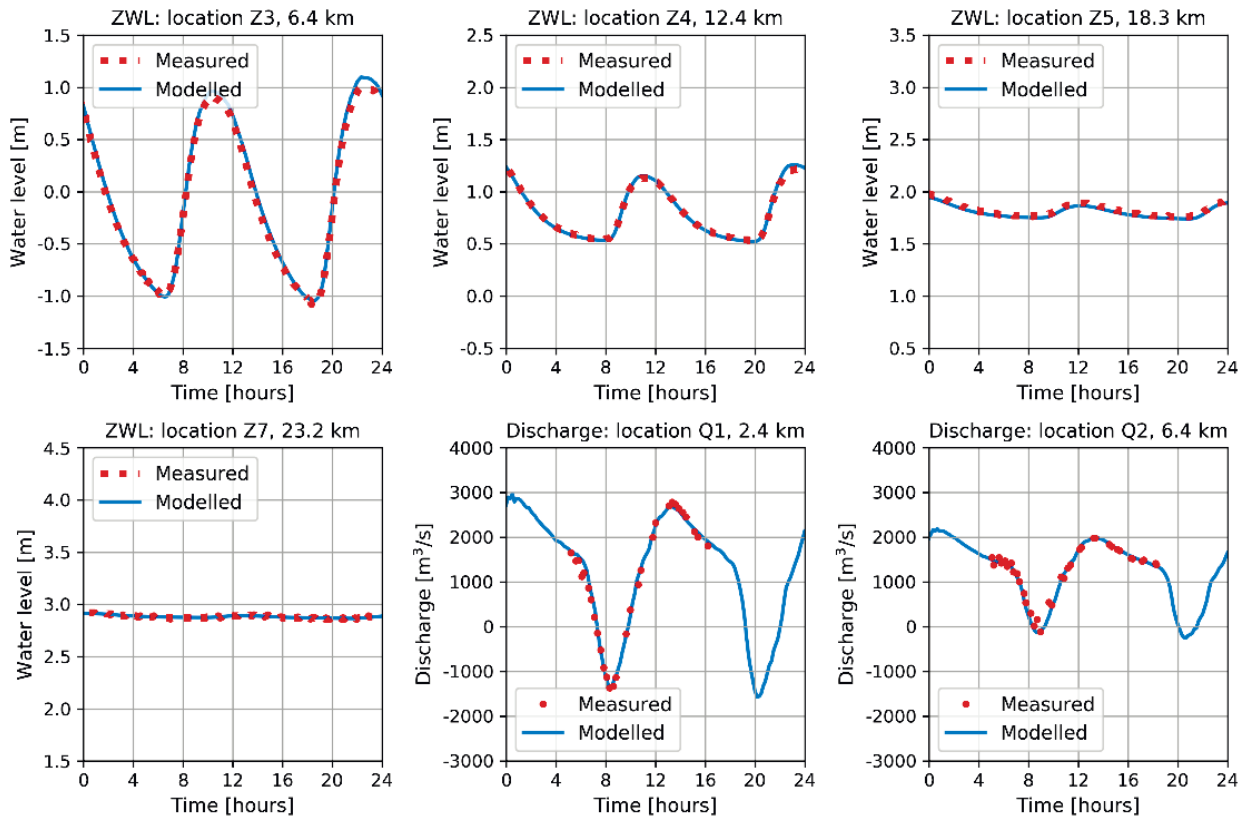

Fig. 2. Model calibration results: water levels and discharges, August 2017.

Also, for the summer period, it was possible to analyze the $2 \mathrm{DH} / 3 \mathrm{D}$ model performance for the depth-averaged velocities as well as for vertical velocity profiles. The comparison for the deepest point at the Q2 cross-section (6.4 km from the mouth) is presented in Fig. 3 . There it can be seen, that velocities are reproduced with high accuracy during both flood and ebb (profiles 2, 3 and 4). A certain deviation between the measurements and the model is observed during the first ebb period (profile 1), where the model overestimates the velocities by about $0.2-0.3 \mathrm{~m} / \mathrm{s}$. The fact that one ebb period is reproduced well while the other is not can be explained by inconsistencies in the discharge measurements at this location, from which the velocities were derived, particularly, by the variation in the boat track throughout the measurements and absence of concurrent GPS position record.
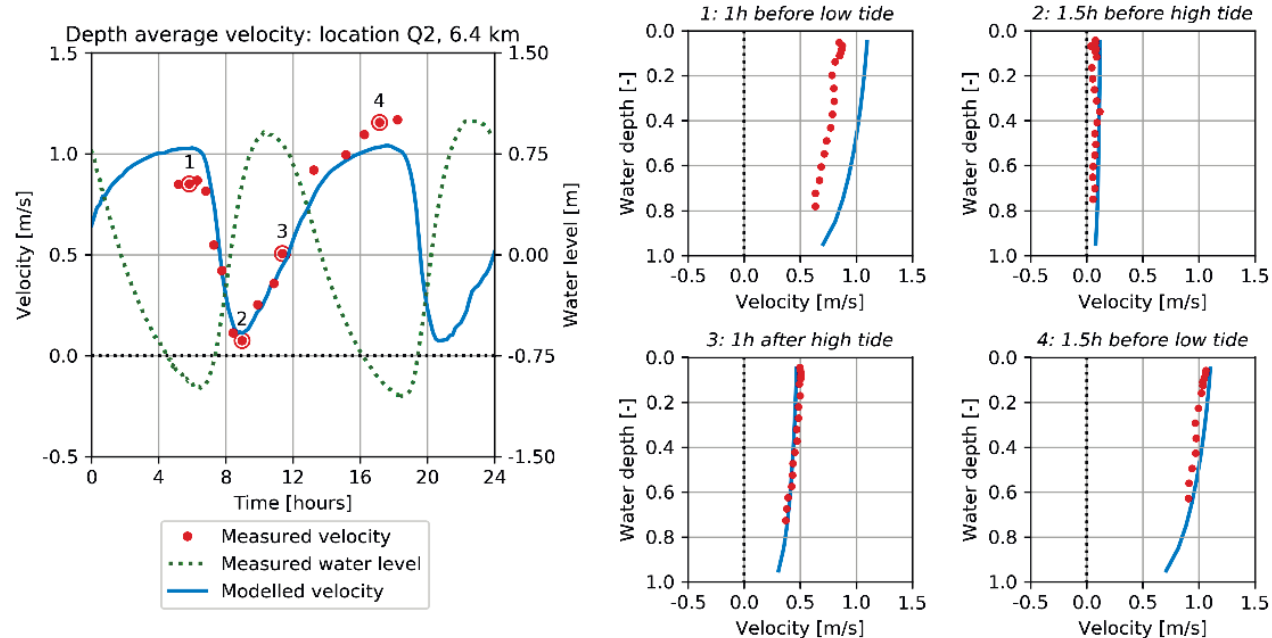

Fig. 3. Model calibration results: depth average velocities and velocity profiles at location Q2 $(6.4 \mathrm{~km}$ from the mouth), water depth for profiles are relative to the total water column height, August 2017. 


\subsection{Winter hydrodynamic conditions}

The results for the winter period were also nearly identical for models in $1 \mathrm{D}$ and 2DH schematizations. First, both models were calibrated based on data collected in January 2019 and, similarly to the summer period, the best results in $2 \mathrm{DH}$ model for the downstream sections were achieved with slightly higher roughness coefficient values: 0.08 compared to 0.07 in the $1 \mathrm{D}$ model. For the most upstream section roughness coefficients were identical for both models. From Table, in which roughness coefficients are presented for both summer and winter calibration, it can be seen that for the winter period their values are up to 3.5 times higher.

The comparison between the modelled and the measured water levels is presented in Figure 4. There it can be seen that for this period the mean water level along with the water level at high tide are underestimated, while the shape of the tidal wave is also distorted and this effect increases towards the upstream: maximum water level is underestimated by about $0.18 \mathrm{~m}$ at location $\mathrm{Z3}(6.4 \mathrm{~km})$ and by $0.25 \mathrm{~m}$ at $\mathrm{Z4}(12.1 \mathrm{~km})$.
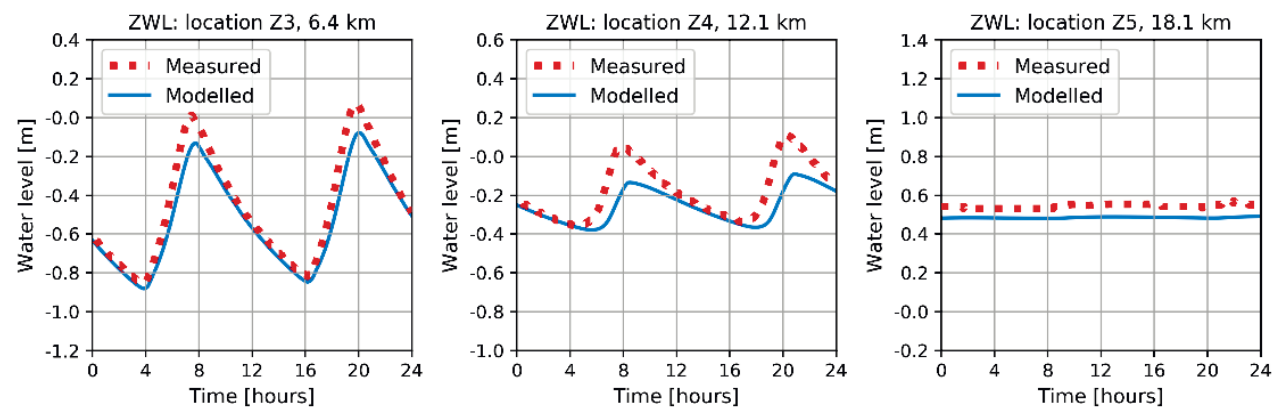

Fig. 4. Model calibration results: water levels, January 2019.

The availability of measured water levels for another period during winter allowed performing validation of the selected roughness characteristics on independent data. The comparison of the model results with the measurements is presented in Fig. 5. A pattern, similar to what was observed during the calibration process, can also be seen for the model validation. The difference between the measured and the modelled tidal range increases towards the upstream: from about $0.2 \mathrm{~m}$ at Z3 (10\% of the tidal range at this location) up to $0.5 \mathrm{~m}(35 \%)$ at Z4 and $0.3 \mathrm{~m}(50 \%)$ - at Z5 $(18.5 \mathrm{~km})$. Accuracy of the model in terms of reproducing the shape of the tidal wave also decreases as it becomes more flattened towards the upstream. As a result, hydrodynamic models of the Onega River estuary for winter conditions can only be used for raw estimations of water levels and discharges and are limited to the downstream part of the area (up to $5-8 \mathrm{~km}$ from the mouth).
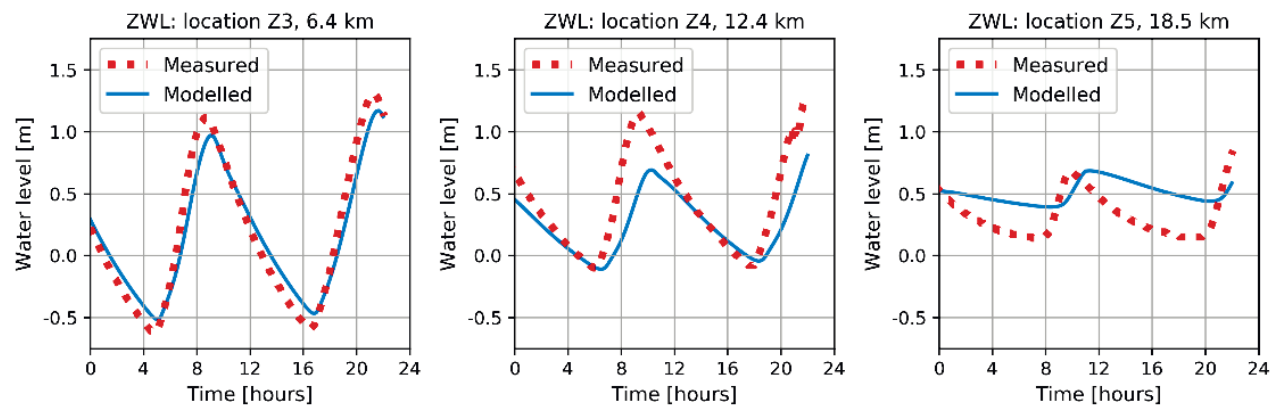

Fig. 5. Model validation results: water levels, January 2017. 


\section{Discussion}

Despite some of the earlier studies showing that reverse currents in a tidal estuary cannot be adequately reproduced using one-dimensional modelling approach based on the SaintVenant equations [5], the results obtained for the tidal estuary of the Onega River for the summer period demonstrate high accuracy in terms of modelling temporal variation of water levels and discharges over a tidal cycle. Moreover, the 1D model results also show good agreement with the results of the $2 \mathrm{DH} / 3 \mathrm{D}$ model, which suggests that it can also be applied for conditions of a relatively large tidal river estuary during summer period if a problem is not specifically focused on either spatial or vertical distribution of the flow velocities allowing for a more rational use of the computation time. Meanwhile, the 2DH/3D model also demonstrated good results in reproducing the depth-averaged velocities and velocity profiles. Overall, the results obtained for the Onega River estuary provide a good foundation for further development of a similar approach for a more complex object, such as the Northern Dvina River delta [6].

For the winter conditions, the modelling has shown an underestimation of the tidal range and distortion of the tidal wave shape, which became more significant towards the upstream parts of the estuary, while also significantly higher bed roughness coefficients had to be used. This can be explained by the fact that for real winter conditions flow is affected by friction not only at the bed but also at the water surface, which is generated by the ice cover that could not be reproduced by either of the models used in this study. Because of that, adjustments in the selected approach are required in order to provide reliable modelling results for the winter conditions.

The research was supported by the Russian Foundation for Basic Research (Project No. 19-35-90032 "Features of the reversible flow dynamics in tidal estuaries of the White Sea" in providing 1D modelling; Project No. 19-35-60032 "Flow dynamics in large tidal delta of the Northern Dvina River, based on the synthesis of computer modelling, stationary and expeditionary hydrological observations" in providing 2DH/3D modeling; Project No. 18- 05-60021 "River runoff and changes in the water and ice-thermal regime of the estuarine regions and the sea coasts of Russian Arctic in the 21 th century" in information and data support).

\section{References}

1. Y. Lupachev, Proceedings of State Oceanographic Institute, 161, pp.92-96 (1982) (in Russian)

2. E. Panchenko, S. Lebedeva, P. Terskii, M. Leummens, IOP Conf. Ser. Earth Env, 263, pp. 1-6 (2019)

3. US Army Corps of Engineers Hydrologic Engineering Center, HEC-RAS River Analysis System Hydraulic Reference Manual, Version 5.0, 547 p. (2016)

4. Deltares, Delft3D-FLOW User Manual, Version 3.15, 694 p. (2018)

5. A. Alabyan, E. Panchenko, Engineering Survey, 3, pp. 71-72 (2017)

6. A. Alabyan, S. Lebedeva, J. Hydroinform., 4, pp. 798-814 (2018) 